\title{
Tinjauan pustaka \\ Mendengkur pada Anak: kapan waktu yang tepat untuk dilakukan tonsiloadenoidektomi?
}

\author{
Bambang Supriyatno \\ Departemen Ilmu Kesehatan Anak Fakultas Kedokteran Universitas Indonesia/RS Dr. Cipto Mangunkusumo, Jakarta
}

\begin{abstract}
Mendengkur atau mengorok adalah suara nyaring yang keluar dari saluran respiratori atas sebagai hasil getaran palatum molle dan uvula. Mendengkur bukanlah suatu diagnosis, melainkan gejala yang harus dicari diagnosisnya. Mendengkur perlu diwaspadai karena dapat menimbulkan masalah respiratori di kemudian hari, dan terbagi dalam dua kelompok besar, yaitu occasional snoring dan habitual snoring. Spektrum mendengkur terdiri dari ringan hingga berat, yaitu primary snoring, upper airway resistance syndrome, obstructive hypoventilation, dan obstructive sleep apnea syndrome (OSAS). Pemeriksaan baku emas untuk membedakan spektrum mendengkur tersebut adalah polisomnografi (PSG), namun pemeriksaan ini belum merata di seluruh daerah. Sebagai alternatif, pemeriksaan lain yang dapat dilakukan adalah poligrafi, pulse-oximetri, rekaman video, dan tape recorder. Faktor risiko utama OSAS pada anak adalah hipertrofi tonsil dan/atau adenoid, dengan demikian kecenderungan tata laksana saat ini adalah tonsiloadenoidektomi (TA). Sebelum tindakan TA, kortikosteroid intranasal, selama 4-8 minggu, dapat diberikan untuk menurunkan ukuran tonsil dan/atau adenoid. Indikasi TA adalah OSAS sedang dan berat pada anak, tonsilitis akut yang berulang, abses peritonsil, dan tersangka keganasan. Pada daerah dengan fasilitas terbatas, TA dapat dipertimbangkan pada habitual snoring yang tidak respons dengan pemberian kortikosteroid intranasal selama 8 minggu. Setelah dilakukan TA, pemantauan lebih lanjut perlu dilakukan untuk melihat proses catch up terhadap pertumbuhan dan perkembangan anak. Sari Pediatri 2015;17(4):317-22.
\end{abstract}

Kata kunci: habitual snoring, obstructive sleep apnea syndrome, polisomnografi, tonsiloadenoidektomi

\section{Review article \\ Snoring in Children: when to perform tonsilloadenoidectomy}

Bambang Supriyatno

Snoring is a high pitched noise from respiratory tract resulted from vibration of palatum molle and uvula. Snoring is not a diagnosis but a symptom, and it can cause serious respiratory problem. Snoring is divided into occasional and habitual snoring. However, its spectrums vary from mild to severe, which are upper airway resistance syndrome, obstructive hypoventilation, dan obstructive sleep apnea syndrome (OSAS). Gold standard examination to diagnose upon snoring spectrum is polysomnography (PSG), yet it has not been performed evenly. Thus, polygraphy, pulse oximetry examinations, video or tape recorder can be utilized as alternatives. Primary risk factor for OSAS is tonsil and/or adenoid hypertrophy, hence tonsilloadenoidectomy (TA) is the main therapy for OSAS. Prior to procedure, nasal corticosteroid can be administered for $4-8$ weeks to decrease tonsil and/or adenoid size. Indications for TA are moderate to severe OSAS, acute and recurrent tonsillitis, peritonsillar abscess, and suspected malignancy. In areas with limited facilities, TA is considered in habitual snoring which is not responding with 8 week course of intranasal corticosteroid. Subsequently after TA, follow up should be performed to monitor child's catch up for growth and development. Sari Pediatri 2015;17(4):317-22.

Keywords: habitual snoring, obstructive sleep apnea syndrome, polysomnography, tonsilloadenoidectomy

\footnotetext{
Alamat korespondensi: Prof. DR. Dr. Bambang Supriyatno, Sp.A(K). Departemen Ilmu Kesehatan Anak Rumah Sakit Cipto Mangunkusumo, Jl. Diponegoro No.71, Senen, Jakarta Pusat. Tel.+62-21-391830111. E-mail: bangsupri@idai.or.id, bangsupri@yahoo.com
} 
Mendengkur merupakan salah satu gejala yang perlu diwaspadai karena dapat menimbulkan masalah respiratori di kemudian hari. Kewaspadaan terhadap gejala mendengkur pada anak di beberapa negara maju cukup tinggi, tetapi di Indonesia masih kurang. Mendengkur pada anak masih dianggap suatu hal yang biasa karena merupakan 'keturunan' dari orangtuanya. ${ }^{1,2}$

Mendengkur terbagi dalam dua kelompok besar, yaitu mendengkur yang jarang timbul (occasional snoring) dan mendengkur yang timbul hampir setiap hari (habitual snoring). Kejadian occasional snoring sekitar 26\%-30\%, sedangkan habitual snoring sekitar 5\%-7\%. ${ }^{2,3}$ Habitual snoring perlu ditindaklanjuti karena dapat berkembang menjadi OSAS (obstructive sleep apnea syndrome) atau bahkan merupakan gejala dari OSAS yang dapat menyebabkan masalah serius pada anak. Kejadian OSAS pada anak berkisar antara 0,1\%-5,7\%, serta semakin meningkat seiring dengan pertambahan usia dan banyaknya faktor risiko terjadinya OSAS seperti obesitas, dan lain-lain. ${ }^{1-4}$

Penanganan yang tepat dan benar terhadap gejala mendengkur sangat berpengaruh terhadap kualitas hidup anak di kemudian hari. Tata laksana mendengkur pada anak tergantung pada derajat beratringannya akibat mendengur tersebut. ${ }^{2,5,6}$

\section{Definisi}

Mendengkur atau mengorok adalah suara nyaring yang keluar dari saluran respiratori atas sebagai hasil dari getaran atap lunak rongga mulut (palatum molle) dan uvula. Occasional snoring adalah frekuensi mendengkur kurang dari 3 kali seminggu, sedangkan habitual snoring adalah frekuensi mendengkur $\geq 3$ kali seminggu. ${ }^{1-3}$

Spektrum mendengkur pada anak terdiri dari ringan sampai berat yaitu primary snoring, upper airway resistance syndrome (UARS), obstructive hypoventilatian
$(\mathrm{OH})$, dan OSAS. Perbedaan spektrum tersebut didasarkan pada patofisiologi dan gejala yang terjadi akibat mendengkur (Tabel 1).

\section{Faktor risiko}

Kejadian mendengkur tertinggi adalah_pada usia 3-6 tahun karena kurang lebih cepatnya perkembangan tonsil dan adenoid dibandingkan dengan perkembangan rongga mulut yang berjalan lambat. Adanya perbedaan percepatan pertumbuhan tersebut mengakibatkan adanya 'sumbatan' atau penyempitan jalan napas. ${ }^{2,3,7}$

Faktor risiko terjadinya OSAS pada anak berbeda dengan orang dewasa. Pada dewasa, obesitas, usia lanjut, serta merokok merupakan faktor risiko utama OSAS, sedangkan pada anak faktor risiko tertinggi adalah hipertrofi tonsil dan adenoid, disproporsi wajah (misalnya sindrom Pierre Robin, sindrom Apert), dan obesitas (pada remaja). ${ }^{1,7,8}$

\section{Diagnosis}

Mendengkur bukanlah suatu diagnosis melainkan suatu gejala yang harus dicari diagnosisnya. Untuk membedakan spektrum mendengkur diperlukan pemeriksaan penunjang sebagai baku emas yaitu polisomnografi (PSG). Polisomnografi adalah pemeriksaan penunjang untuk menentukan adanya apnea atau hipopnea pada anak saat tidur akibat sumbatan jalan napas. PSG dapat menentukan frekuensi apnea atau hipopnea selama 1 jam saat tidur yang dikenal dengan istilah AHI (apnea-hypopnea index). ${ }^{1-3,9}$

Pada dewasa, penentuan nilai AHI sebagai cutoff point diagnosis OSAS sudah disepakati yaitu $\geq 5$, sedangkan pada anak masih ada perbedaan pendapat. Beberapa penulis menyebut OSAS apabila

Tabel 1. Spektrum mendengkur pada anak

\begin{tabular}{lccccc}
\hline & Mendengkur & Usaha napas & Kelainan AGD & Hipopnea/ Apnea & Kelainan PSG \\
\hline PS & + & + & - & - & - \\
UARS & + & + & - & - & - \\
OH & + & + & + & - & - \\
OSAS & + & + & + & + & + \\
\hline
\end{tabular}

*)PS: primary snoring; UARS: upper airway resistance syndrome; OH: obstructive hypoventilation; OSAS: obstructive sleep apnea syndrome; AGD: analisis gas darah; PSG: polisomnografi. ${ }^{2}$ (modifikasi) 
nilai AHI lebih atau sama dengan 1, tetapi ada juga yang menggunakan kriteria 3 atau 5 , dengan kecenderungan ke arah $\geq 1$ karena harus lebih agresif dalam penanganannya.

Polisomnografi merupakan pemeriksaan penunjang yang sulit tersedia di negara berkembang. Di Indonesia, pemeriksaan ini belum merata sehingga diperlukan suatu pemeriksaan alternatif, seperti poligrafi, pulse-oxymetri, rekaman video, dan rekaman suara (tape-recorder) dengan berbagai kekurangan dan kelebihannya. ${ }^{3,8-10}$

Pemeriksaan PSG dapat membedakan apnea atau hipopnea yang terjadi karena sumbatan jalan napas atau karena kelainan sentral sedangkan pemeriksaan penunjang yang lain tidak dapat membedakannya. Penentuan jenis apnea atau hipopnea penting untuk tata laksana selanjutnya. Pada apnea atau hipopnea karena sumbatan jalan napas, tindakan pembebasan jalan napas merupakan pilihan utama sedangkan pada kasus dengan apnea sentral tidak memerlukan pembebasan jalan napas. Salah satu cara pembebasan jalan napas adalah dengan pengangkatan tonsil dan adenoid atau dikenal tonsilo-adenoidektomi. ${ }^{2,7}$

Urutan pemeriksaan penunjang dari yang paling baik dilakukan selain polisomnografi adalah poligrafi, pulse-oxymetri, rekaman video, dan tape-recorder. Pada poligrafi dapat dilihat adanya apnea atau hipopnea, namun tidak dapat dibedakan antara apnea karena sentral atau sumbatan jalan napas., ${ }^{2,7}$

Pemantauan dengan menggunakan pulse-oxymetri selama tidur dapat mendeteksi penurunan saturasi saat tidur tetapi pemeriksaan ini masih sulit diaplikasikan karena pemantauan tidak akurat. Kesulitan penggunaan pulse-oxymetri adalah apabila elektroda terlepas dan nilai saturasi tidak terpantau. Bila ditemukan penurunan saturasi yang periodik di pemeriksaan ini, perlu dicurigai kemungkinan OSAS. ${ }^{2,7,9}$

Penggunaan video dan tape recorder dapat mengindikasikan adanya apnea atau hipopnea yaitu bila terdapat gambar atau suara yang menunjukkan henti napas selama 10 detik. Pemeriksaan penunjang ini tidak dapat membedakan etiologi sentral atau sumbatan. Kendala lain adalah sulitnya merekam selama 24 jam atau selama tidur terus menerus. ${ }^{10}$

Salah satu cara menentukan diagnosis yang tidak menggunakan alat adalah sistem skor. Penggunaan sistem skor ini dianggap hanya sebagai uji tapis untuk melakukan pemeriksaan lanjutan karena mempunyai sensitivitas dan spesifisitas yang kurang baik. ${ }^{2,8,10}$

\section{Tata laksana}

Faktor risiko utama OSAS pada anak adalah hipertrofi tonsil dan/atau adenoid sehingga kecenderungan tata laksana saat ini adalah melakukan tindakan tonsiloadenoidektomi (TA). Saat ini, tindakan TA lebih agresif untuk mencegah terjadinya komplikasi OSAS di kemudian hari. Tindakan TA yang agresif ini masih kontroversial karena hubungannya dengan sistem imunitas tubuh oleh tonsil dan atau adenoid. ${ }^{11-13}$

Selain itu, belum ada kesepakatan penentuan waktu yang tepat untuk melakukan tindakan TA. Walaupun demikian, pada kasus-kasus yang berat dengan tonsil dan/atau adenoid yang sangat menganggu, para ahli sepakat untuk melakukan TA. Para ahli yang menyetujui tindakan TA berpendapat bahwa walaupun tonsil dan adenoid berperan dalam mempertahankan daya tahan tubuh tetapi dengan sering terjadinya infeksi berulang (tonsilitis kronis dan berulang), tumbuh kembang anak akan terganggu. Dengan dasar fungsi imunitas tubuh dapat digantikan oleh organ lain seperti limpa maka pengangkatan tonsil atau adenoid sesuai indikasi tidak mengganggu daya tahan tubuh secara keseluruhan, ${ }^{14}$

Para ahli sepakat sebelum tindakan TA, kortikosteroid intranasal diberikan untuk menurunkan ukuran hipertrofi tonsil dan/atau adenoid. Jenis kortikosteroid yang diberikan bermacam-macam, antara lain mometason, flutikason, budesonid, dan flunisonid. Pemilihan kortikosteroid intranasal harus berdasarkan kepada bioavailabilitas yang rendah seperti mometason atau flutikason dengan tujuan mengurangi efek samping kortikosteroid. ${ }^{15-17}$

Dosis pemberian kortikosteroid intranasal adalah 100-200 ug budesonid atau yang setara, selama 4-8 minggu. Pada keadaan OSAS ringan, pemberian kortikosteroid intranasal memberikan efek yang cukup baik, tetapi pada saat sudah terjadi OSAS yang berat maka pemberian kortikosteroid intranasal umumnya tidak berhasil. ${ }^{15-17}$

Beberapa tata laksana yang digunakan adalah penggunaan CPAP (continous positive airway pressure), penurunan berat badan, ataupun rekonstruksi disproporsi wajah. Penggunaan CPAP dilakukan apabila faktor utama adalah bukan hipertrofi tonsil dan adenoid tetapi disertai faktor risiko lain seperti obesitas dan disproporsi wajah. ${ }^{2,12}$ 


\section{Tonsilo-Adenoidektomi}

Idealnya, sebelum melakukan tindakan TA perlu dilakukan pemeriksaan PSG untuk menentukan jenis kelainannya yaitu primary snoring, UARS, $\mathrm{OH}$, atau OSAS. Pada primary snoring, UARS, HO dan OSAS ringan, pemberian kortikosteroid intranasal selama 4-8 minggu mempunyai efek yang baik (gejala mendengkur berkurang secara nyata). ${ }^{18}$

Indikasi TA jika didapat hipertrofi tonsil dan adenoid ditambah dengan klinis yang sering dijumpai pada OSAS, seperti mulut terbuka saat bernapas, suara napas parau, hipertensi, hiperaktif, enuresis, mengantuk pada siang hari (day time somnolence), dan cenderung gizi kurang ke arah buruk. Pada keadaan tersebut dapat dilakukan tindakan TA sebagai tindakan awal dan agresif untuk mencegah terjadinya komplikasi yang lebih berat. Pasca-tindakan TA perlu dilakukan pemantauan tindak lanjut untuk melihat perubahan yang terjadi pasca-tindakan., ${ }^{2,19}$

Pada OSAS yang sedang dan berat, pemberian kortikosteroid intranasal bertujuan untuk persiapan tindakan TA. Tujuan pemberian kortikosteroid intranasal adalah untuk mengecilkan ukuran tonsil dan atau adenoid. Dengan demikian, sumbatan tidak terlalu berat dan peningkatan intratorakal tidak terlalu tinggi sehingga mudah diatasi. Pada keadaan tonsil dan adenoid yang besar, terjadi peningkatan tekanan intra torakal yang akan menyebabkan kelainan jantung pasca tindakan. ${ }^{20}$

Pada keadaan tidak tersedia PSG maka dapat dilakukan pulse-oxymetri atau rekamam video. Dengan alat tersebut dapat dilihat proses henti napas (apnea atau hipopnea) secara kasat mata dengan penurunan saturasi selama pemantauan dengan pulse-oxymetri atau adanya arousal (terjaga saat tidur) pada saat direkam. Dengan keadaan seperti ini maka dapat diduga telah terjadi OSAS. ${ }^{2,10,}$

Arousal atau penurunan saturasi merupakan indikasi untuk melakukan persiapan tonsilo-adenidektomi dengan pemberian kortikosteroid intranasal. Dengan pemberian kortikosteroid intranasal selama 4-8 minggu dengan dosis $2 \times 100$ ug diharapkan kejadian arousal dan penurunan saturasi berkurang. Respons yang baik terhadap pemberian kortikosteroid intranasal menunjukkan bahwa tindakan TA belum perlu dilakukan karena sumbatan jalan napas berkurang. ${ }^{16,18}$

Dalam hal respons terhadap kortikosteroid intranasal tidak berhasil maka perlu dipertimbangkan tindakan TA apabila faktor risiko utama adalah hipertrofi tonsil dan/atau adenoid. Tindakan TA mempunyai angka keberhasilan yang sangat tinggi yaitu 75\%-100\% tergantung dari ada tidaknya faktor risiko lainnya seperti obesitas atau disproporsi wajah. $^{13,14}$

Penelitian menunjukkan pasca-tindakan TA, anak akan mengalami pertumbuhan yang nyata untuk mengejar ketinggalan pertumbuhannya. Berat badan akan meningkat dengan cepat serta perkembangan akan lebih baik. ${ }^{21}$

\section{Pro-kontra pemeriksaan PSG Pra-Ton- siloadenoidektomi}

Beberapa ahli sepakat indikasi tindakan TA adalah OSAS sedang dan berat pada anak, tonsilitis akut yang berulang, abses peritonsil, dan tersangka keganasan. ${ }^{19}$ Penentuan diagnosis OSAS secara definitif menggunakan PSG sebagai baku emas. Dengan pemeriksaan PSG dapat dibedakan antara PS, UARS, $\mathrm{OH}$ atau OSAS bergantung didapatkannya nilai AHI. Tanpa PSG nilai AHI tidak dapat ditentukan karena harus menghitung jumlah apnea dan/atau hipopnea selama 1 jam yang tidak mungkin dilakukan dengan alat lain. ${ }^{2}$

Permasalahannya adalah PSG tidak tersedia di semua tingkat layanan kesehatan sehingga sulit apabila harus menggunakan PSG sebagai satu-satunya alat yang dapat dipakai sebagai diagnosis. Di negara maju sekalipun, pemeriksaan PSG tidak ada di semua tingkat sehingga harus menunggu waktu giliran untuk dikerjakan dan memerlukan waktu yang sangat lama. Di sisi lain harga yang diperlukan cukup mahal sehingga anak dengan mendengkur harus menunggu lama untuk menentukan tindakan TA. 2,10

Berdasarkan hal tersebut beberapa ahli sepakat apabila PSG tidak dapat dikerjakan, untuk menentukan tindakan TA diperlukan beberapa kriteria. Idealnya, pemeriksaan PSG dilakukan sebelum dan sesudah dilakukan tindakan TA sehingga dapat diketahui efikasi tindakan tersebut. ${ }^{2,10,21}$

Dengan pertimbangan ketersediaan PSG, adanya kemungkinan arousal, dan rekaman video maka pada anak dengan habitual snoring sebaiknya langsung diberikan kortikosteroid intranasal 4-8 minggu. Apbila dengan pengobatan tersebut tidak menunjukkan 
respons sementara dicurigai tonsil dan/atau adenoid sebagai faktor risiko utama maka dapat dilakukan tindakan TA pada anak di atas usia 3- 6 tahun $^{2}$

\section{Penutup}

Mendengkur pada anak bukan merupakan diagnosis, tetapi gejala yang harus dicari etiologinya untuk menentukan tindakan selanjutnya. Spektrum mendengkur terdiri dari primary snoring, upper airway resistance syndrome, dan OSAS yang berbeda dalam gejala dan kelainan yang terjadi. Untuk membedakan spektrum mendengkur diperlukan pemeriksaan polisomnografi sebagai baku emas. Faktor risiko mendengkur adalah hipertrofi tonsil dan/atau adenoid, disproporsi wajah, dan obesitas. Tata laksana mendengkur adalah dengan kortikosteroid intranasal selama 4-8 minggu. Namun, jika tidak respons, tindakan tonsiloadenoidektomi merupakan pilihan utama dengan angka keberhasilan yang tinggi (75\%-100\%). Indikasi tonsiloadenoidektomi adalah OSAS sedang dan berat, tonsilitis berulang, abses peritonsil, dan keganasan.

Untuk menentukan waktu yang tepat melakukan tonsiloadenoidektomi adalah pada anak dengan habitual snoring perlu dilakukan pemeriksaan PSG untuk menentukan diagnosis OSAS. Pada OSAS sedang dan berat merupakan indikasi tonsiloadenoidektomi dengan persiapan pemberian kortikosteroid intranasal. Pada pelayanan kesehatan yang tidak mempunyai PSG, pada anak dengan habitual snoring dapat dilakukan pemeriksaan penunjang, seperti poligrafi, pulse-oxymetri, rekaman video yang mengarah ke OSAS. Apabila dicurigai OSAS, persiapkan untuk tonsiloadenoidektomi. Di daerah yang tidak mempunyai fasilitas apapun dapat dipertimbangkan tindakan tonsiloadenoidektomi pada anak dengan habitual snoring yang tidak respons terhadap pemberian kortikosteroid intranasal selama 8 minggu. Pasca-tindakan tonsiloadenoidektomi akan terjadi proses 'catch-up' terhadap pertumbuhan dan perkembangan anak.

\section{Daftar pustaka}

1. Anuntaseree W, Kuasirikul S, Suntornlohanakul S. Natural history of snoring and obstructive sleep apnea in Thai school-age children. Pediatr Pulmonol
2005;39:415-20.

2. Marcus CL, Brooks LJ, Draper KA, Gozal D, Halbower AC, Jones J, dkk. Diagnosis and management of childhood obstructive sleep apnea syndrome. Pediatrics 2012;130:576-84.

3. Lumeng JC, Chervin RD. Epidemiologiy of pediatric obstructive sleep apnea. Proc Am Thorac Soc 2008;5: 242-52.

4. Supriyatno B, Deviani R, Tumbelaka A, Kariani EBK, Rahajoe NN. Characteristics and risk factors of snoring and the prevalence of suspected obstructive sleep apnea in children. Pediatr Indones 2005;45:40-5.

5. Li AM, Zhu Y, Au CT, Lee DLY, Ho C, Wing YK. Natural History of Primary Snoring in School-aged Children: A 4-Year Follow-up Study. Chest 2013;143:729-35.

6. Garetz SL, Arbor A. Behavior, cognition, and quality of life after adenotonsillectomy for pediatric sleepdisordered breathing: Summary of the literature. Otolaryngol-Head and Neck Surg 2008;138:S19-26.

7. Chang SJ, Chae KY. Obstructive sleep apnea syndrome in children: Epidemiology, pathophysiology, diagnosis and sequelae. Korean J Pediatr 2010;53:863-71.

8. Supriyatno B, Said M, Hermani B, Sjarif DR, Sastroasmoro S. Risk factors of obstructive sleep apnea syndrome in obese early adolescents: A prediction model using scoring system. Acta Med Indones 2010;42:152-7.

9. Muzumdar H, Arens R. Diagnostic Issues in pediatric obstructive sleep apnea. Proc Am Thorac Soc 2008;5:26373.

10. Rosen CL, Wang R, Taylor G, Marcus CL, Katz ES, Paruthi S, dkk. Utility of symptoms to predict treatment outcomes in obstructive sleep apnea syndrome. Pediatrics 2015; 135:e662-71.

11. Gigante J. Tonsillectomy and adenoidectomy. Pediatr Rev 2005;26:199-203.

12. Powell S, Wilson J. Paediatric tonsillectomy-What has literature added in the last 5 years? Otorhinolaryngologist 2012;5:139-46.

13. Ye J, Liu H, Zhang GH, Li P, Yang QT, Liu X, dkk. Outcome of adetonsillectomy for obstructive sleep apnea syndrome in children. Ann Otol Rhinol Laryngol 2010;119;506-13.

14. Marcus CL, Moore RH, Rosen CL, Giordani B, Garetz SL, Taylor G, dkk. The randomized trial of adenotonsillectomy for childhood sleep apnea. N Engl J Med 2013;368;2366-76.

15. Jung YG, Kim HY, Min JY, Dhong HJ, Chung SK. Role of intranasal topical steroid in pediatric sleep disorders 
breathing and influence of allergy, sinusitis, and obesity on treatment outcome. Clin Exp Otorhinolaryngol 2011;4:27-32.

16. Gupta V, Gupta M, Matreja PS, Singh S. Efficacy of mometasone nasal spray in children with snoring due to adenoids. Clin Rhinol An Int J 2014;7:1-4.

17. Chadha NK, Zhang L, Mendoza-Sassi RA, Cesar JA. Using nasal steroids to treat nasal obstruction caused by adenoid hypertrophy: Does it work?. Otorhinol Head Neck Surg 2009;140:139-47.

18. Sobhy TS. Role of intranasal steroid in the prevention of recurrent symptoms after adenoidectomy. Diakses pada 27 November 2015. Didapat dari:http://dx.doi. org/10.1155/2013/603493.

19. Mu SC, Cheng I, Chiang RPY, Sung TC. Concise indications for adenoidectomy-tonsillectomy in children with obstructive sleep apnea syndrome. J Pediatr Resp Dis 2013;9:11-21.

20. Tagaya M, Nakata, Yasumo F, Miyazaki S, Sasaki F, Morinaga M, dkk. Relationship between adenoid size and severity of obstructive sleep apnea in preschool children. Int J Pediatr Otorhinolaryngol 2012;76:1827-30.

21. Katz ES, Moore RH, Rosen CL, Mitchell RB, Amin R, Arens R, dkk. Growth after adenonsillectomy for obstructive sleep apnea: An RCT. Pediatrics 2014;134:282-9. 